\title{
Total laparoscopic Wertheim's radical hysterectomy versus Wertheim's radical abdominal hysterectomy in the management of stage I cervical cancer in Singapore: a pilot study
}

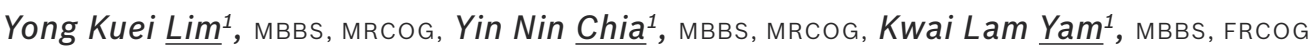

\begin{abstract}
INTRODUCTION For many decades, Wertheim's radical hysterectomy via laparotomy, also known as Wertheim's radical abdominal hysterectomy (RAH), has been the traditional surgical approach for operable stage IB cervical cancer. However, many established cancer centres worldwide have recently shown total laparoscopic Wertheim's radical hysterectomy (TLRH) to be a safe and feasible alternative to the conventional abdominal route for early cervical cancer management. This technique was introduced in Singapore in 2009.

METHODS This was a prospective pilot study comparing TLRH with RAH in a single large tertiary institution in Singapore. Inclusion criteria included surgically fit patients with early cervical cancer and no radiological evidence of regional or distant metastases.

RESULTS From November 2009 to February 2011, a total of 18 TLRHs and 30 RAHs were performed. The median blood loss in the TLRH group was significantly lower than that in the RAH group ( $300 \mathrm{~mL}$ vs. $500 \mathrm{~mL}$; $p=0.04)$. However, there was no statistically significant difference found between the two techniques in terms of operative time, hospital stay, bladder recovery, total lymph node yield or adjuvant treatment. No intraoperative bladder, ureteric or bowel complications were observed in the two groups. Postoperative complications occurred in $2(11.1 \%) \mathrm{TLRH}$ patients and $4(13.3 \%)$ RAH patients. With a median follow-up of 37.3 (range 10-68) weeks, the rate of recurrence was found to be $5.6 \%$ for the TLRH group and $10.0 \%$ for the RAH group.

CONCLUSION The results of our study suggest that with appropriate patient selection and increased experience, TLRH can be a safe and effective procedure for the management of early cervical cancer in Singapore.
\end{abstract}

Keywords: cervical cancer, laparoscopic radical hysterectomy

\section{INTRODUCTION}

The standard surgical treatment for early cervical cancer (i.e. International Federation of Gynecology and Obstetrics [FIGO] stages IA2 to IIA) is Wertheim's radical abdominal hysterectomy $(\mathrm{RAH})$ with systematic bilateral pelvic lymphadenectomy. However, over the last two decades, technological advancement has allowed oncologic surgeries to be performed using minimally invasive routes. Laparoscopic radical hysterectomy with pelvic lymphadenectomy was first reported in the early $1990 \mathrm{~s}^{(1,2)}$ and with increased experience in the technique, several large cancer centres have in the last decade reported its technical efficacy and safety. ${ }^{(3-15)}$ The main advantages of laparoscopic surgery include low amount of blood loss, short hospitalisation period, early recovery and reduced wound infection. Although no large randomised studies have been conducted to date, the results of recent cohort studies with long-term follow-up suggest that the oncologic outcome of laparoscopic surgery is comparable to surgery using the traditional laparotomy route. ${ }^{(3-15)}$ Thus, the aim of this article is to describe the early experience of total laparoscopic Wertheim's radical hysterectomy (TLRH) in the management of early cervical cancer in Singapore. This is the first and largest series reported in Singapore.

\section{METHODS}

This was a prospective study conducted by the Department of Gynaecologic Oncology, KK Women's \& Children's Hospital, Singapore, between November 2009 and February 2011. The inclusion criteria were: (a) early cervical cancer, defined as FIGO (2009)(16) stage IA to IB2 cervical cancer; and (b) clinical and radiological absence of lymph node and distant metastases. The exclusion criteria were: (a) an age of more than 70 years; (b) a uterus that was more than 12 weeks in size; (c) pregnancy; and (d) previous midline laparotomies. Patients who were medically unfit and/or had pre-existing medical conditions, for which pneumoperitoneum is contraindicated, were also excluded from the study.

Patients who met the criteria were counselled and offered the option of undergoing TLRH. They were informed of the risks and possible complications of the laparoscopic procedure, and those who opted for TLRH signed the appropriate consent form. The patients were also informed

'Department of Gynaecologic Oncology, KK Women's \& Children's Hospital, Singapore

Correspondence: Dr Lim Yong Kuei Timothy, Consultant, Department of Gynaecologic Oncology, Level 6, Women's Tower, KK Women's \& Children's Hospital, 100 Bukit Timah Road, Singapore 229899. yongkuei@hotmail.com 
of the possibility of conversion to laparotomy, in the event it was considered technically unsafe to proceed with laparoscopy. Patient demographics, intraoperative and postoperative outcomes, and pathology were recorded prospectively.

In TLRH, patients were first placed in the low lithotomy position. The uterine manipulator was not used in most cases, and surgery was carried out via four laparoscopic ports. A 12-mm balloon trocar (Kii Balloon blunt tip system; Applied Medical, Rancho Santa Margarita, CA, USA) was placed through the umbilicus via the Hasson technique. The laparoscope was inserted through the port created via the Hasson technique, and an intraperitoneal survey was performed to exclude peritoneal disease and check for suitability to proceed with laparoscopic surgery. Two 5-mm side trocars were placed at the right and left middle quadrants, just below the level of the umbilicus, and an additional disposable trocar Versaport $^{\mathrm{TM}}$ Plus bladeless 5-12-mm trocar; Covidien, Mansfield, MA, USA) was inserted at the midline above the symphysis pubis.

TLRH began with the development of the pelvic spaces (i.e. the paravesical, obturator and pararectal spaces). The external iliac, internal iliac, obturator and common iliac lymph nodes were systematically removed en bloc through the suprapubic port using either the Harmonic ACE ${ }^{\circledR}$ curved shears (Ethicon Endo-Surgery LLC, Somerville, NJ, USA) or bipolar curved forceps (Olympus, Tokyo, Japan). Any suspiciouslooking pelvic lymph node was sent for frozen section, and if positive for metastatic disease, radical hysterectomy was abandoned. The ureters were dissected off the medial peritoneal attachments by blunt dissection and mobilised down to the uterine arteries. The uterine artery and vein were transected at the point of origin from the internal iliac vessels using the Harmonic $\mathrm{ACE}^{\circledR}$ curved shears. The round ligaments were transected, the vesicouterine fold was incised with monopolar scissors, and the bladder was mobilised down to the level of the vagina. The ureteric tunnels were developed, followed by division of the vesicouterine ligaments and dissection of the ureters down to the point of their entry into the bladder. After that, the bladder was further mobilised inferiorly to ensure adequate vaginal margins.

The infundibulopelvic ligaments were transected when bilateral salpingo-oophorectomy was performed. If the ovaries were conserved, the utero-ovarian ligaments were transected. The peritoneal interface between the rectum and posterior vagina was incised in order to enter the rectovaginal space. Both uterosacral ligaments were exposed and transected. Lastly, the parametrial tissues were taken before colpotomy. A LiNA colpotomy tube (LiNA Medical, Devon, UK) was used to assist the vaginal incision and ensure adequate surgical margins $(1-2 \mathrm{~cm})$. The specimen, including the uterus, cervix, parametria and upper vagina margin, was removed vaginally. The vaginal cuff was sutured either laparoscopically or transvaginally.
All patients had a Foley catheter inserted and left in place for about 14 days before a trial off catheter. The catheter was not reinserted if the residual urine was less than $50 \mathrm{~mL}$. For patients who underwent a modified radical hysterectomy (i.e. type II radical hysterectomy), the catheter was removed within five days.

Patients with high risk features or had lymph node metastases received adjuvant treatment. All patients were followed up every three months in the first two years, followed by six-monthly check-ups for the subsequent three years. Systemic examination, including pelvic examination and vaginal vault smear, was performed at each visit. If there was any suspicion of a recurrence, radiological imaging and tissue biopsy were performed.

Mann-Whitney $U$ test and chi-square test were used for statistical analysis. Categorical variables were reported as proportion, while continuous variables were reported as median and range values. All analyses were performed in relation to treatment modality, using the Statistical Package for the Social Sciences version 15 (SPSS Inc, Chicago, IL, USA). All statistical tests were two-sided with exact significance reported. A p-value of $<0.05$ was considered statistically significant.

\section{RESULTS}

From November 2009 to February 2011, 92 patients with cervical cancers ranging from FIGO stages IA to IB2 were treated in KK Women's \& Children's Hospital, Singapore. Of the 56 patients who met the inclusion criteria, 18 consented to TLRH and bilateral pelvic lymphadenectomy, and 30 underwent $\mathrm{RAH}$. The remaining eight patients underwent a simple hysterectomy and were excluded from analysis. The patient and tumour characteristics are presented in Table I. The median age and body mass index (BMI) of the patients who underwent TLRH at diagnosis were 48 years and $22.9 \mathrm{~kg} / \mathrm{m}^{2}$, respectively. Most of the patients were of Chinese ethnicity $(77.8 \%)$ and only $2(11.1 \%)$ were smokers. There was no statistical difference in age, parity, BMI, FIGO stage or tumour size between the TLRH and RAH groups. However, there was a difference in tumour histology between the TLRH and RAH groups; the most common histology observed in the TLRH group was endocervical adenocarcinoma (50.0\%), while that in the RAH group was squamous cell carcinoma $(70.0 \%)$ $(p=0.02)$.

The surgical outcome data is presented in Table II. The median blood loss in the RAH group was significantly higher than that in the TLRH group $(500 \mathrm{~mL}$ vs. $300 \mathrm{~mL} ; \mathrm{p}=0.04$ ). The median operative time for the TLRH group (268 mins) was longer than that of the RAH group (240 mins), but this did not reach statistical significance $(p=0.44)$. The median hospital stay was five days for the TLRH group and six days for the $\mathrm{RAH}$ group - this difference was not statistically significant $(p=0.09)$. 
Table I. Characteristics of the patients and the tumours.

\begin{tabular}{|c|c|c|c|}
\hline \multirow[t]{2}{*}{ Characteristic } & \multicolumn{2}{|c|}{ No. (\%) } & \multirow[t]{2}{*}{ p-value } \\
\hline & TLRH $(n=18)$ & RAH $(n=30)$ & \\
\hline Age* (yrs) $^{*}$ & $48(30-65)$ & $47(33-67)$ & 0.58 \\
\hline Parity* & $2(0-8)$ & $2(0-7)$ & 0.85 \\
\hline $\mathrm{BMI}^{*}\left(\mathrm{~kg} / \mathrm{m}^{2}\right)$ & $22.9(16.0-33.7)$ & $22.4(17.9-33.9)$ & 0.53 \\
\hline $\begin{array}{l}\text { Smoker } \\
\text { Yes } \\
\text { No }\end{array}$ & $\begin{array}{r}2(11.1) \\
16(88.9)\end{array}$ & $\begin{array}{c}2(6.7) \\
28(93.3)\end{array}$ & 0.57 \\
\hline $\begin{array}{l}\text { Ethnicity } \\
\text { Chinese } \\
\text { Malay } \\
\text { Others }\end{array}$ & $\begin{array}{r}14(77.8) \\
2(11.1) \\
2(11.1)\end{array}$ & $\begin{array}{r}24(80.0) \\
3(10.0) \\
3(10.0)\end{array}$ & 0.98 \\
\hline $\begin{array}{l}\text { FIGO stage } \\
\text { IA1 } \\
\text { IB1 } \\
\text { IB2 } \\
\text { IIA }\end{array}$ & $\begin{array}{r}2(11.1) \\
13(72.2) \\
3(16.7) \\
0(0.0)\end{array}$ & $\begin{aligned} 1 & (3.3) \\
23 & (76.7) \\
4 & (13.3) \\
2 & (6.7)\end{aligned}$ & 0.62 \\
\hline Tumour size* $(\mathrm{cm})$ & $2.75(0.1-6)$ & $3(0.2-5)$ & 0.82 \\
\hline $\begin{array}{l}\text { Histology } \\
\text { Squamous cell } \\
\text { carcinoma }\end{array}$ & $6(33.3)$ & $21(70.0)$ & 0.02 \\
\hline $\begin{array}{l}\text { Endocervical } \\
\text { adenocarcinoma }\end{array}$ & $9(50.0)$ & $7(23.3)$ & \\
\hline $\begin{array}{l}\text { Adenosquamous } \\
\text { carcinoma }\end{array}$ & $2(11.1)$ & $1(3.3)$ & \\
\hline Other & $1(5.6)$ & $1(3.3)$ & \\
\hline
\end{tabular}

* Data is presented as median (range).

FIGO: International Federation of Gynecology and Obstetrics; RAH: Wertheim's radical abdominal hysterectomy; TLRH: total laparoscopic Wertheim's radical hysterectomy

In the TLRH group $(\mathrm{n}=18)$, serious intraoperative complication of haemorrhage from the parametrial vessels, which required conversion to laparotomy, was encountered in $1(5.6 \%)$ patient. No intraoperative bladder, ureteric or bowel complications were encountered. There was a total of $2(11.1 \%)$ postoperative complications encountered in the TLRH group - one patient suffered from long-term voiding disorder that required intermittent self-catheterisation, while another patient had a right ureterovaginal fistula that developed 10 days after surgery. For the latter patient, the insertion of a double J stent stopped urine leakage from the vagina. Fortunately, the fistula closed spontaneously after six weeks, and the stent was removed uneventfully. In the RAH group $(n=30)$, there was a total of $4(13.3 \%)$ postoperative complications, namely postoperative wound infection and breakdown. There was no intraoperative complication in the RAH group.

No statistical difference was found between the number of lymph nodes removed in the TLRH group and that removed in the RAH group (26 vs. 22, p = 0.48). Although there was no radiological or clinical evidence of lymph node metastases in the TLRH group, lymphovascular space invasion (LVSI) was seen in $8(44.4 \%)$ patients and $4(22.2 \%)$ had micrometastases, mainly to the obturator nodes. Microscopic parametrial involvement was observed in $2(11.1 \%)$ patients and microscopic vaginal involvement in $4(22.2 \%)$ patients (Table III). There was no statistical difference in the presence of LVSI, lymph
Table II. Surgical outcomes of the patients.

\begin{tabular}{lccc}
\hline Outcome & \multicolumn{2}{c}{ Median (range) } & p-value \\
\cline { 2 - 3 } & TLRH $(\mathbf{n}=\mathbf{1 8})$ & RAH $(\mathbf{n}=\mathbf{3 0})$ & \\
\hline $\begin{array}{l}\text { Operative } \\
\text { time (mins) }\end{array}$ & $268(216-480)$ & $240(128-388)$ & 0.44 \\
$\begin{array}{l}\text { Blood loss (mL) } \\
\text { Hospital stay }\end{array}$ & $500(100-1,000)$ & $500(180-6,000)$ & 0.04 \\
$\begin{array}{l}\text { (days) } \\
\begin{array}{l}\text { Bladder } \\
\text { recovery (days) }\end{array}\end{array}$ & $6(3-29)$ & 0.09 \\
$\begin{array}{l}\text { No. of lymph } \\
\text { nodes removed }\end{array}$ & $26(19-49)$ & $21.0(3.0-50.0)$ & 0.65 \\
\hline
\end{tabular}

RAH: Wertheim's radical abdominal hysterectomy; TLRH: total laparoscopic Wertheim's radical hysterectomy

Table III. Histological risk factors of the patients and the adjuvant therapy received.

\begin{tabular}{lccc}
\hline \multirow{2}{*}{ Variable } & \multicolumn{2}{c}{ No. (\%) } & p-value \\
\cline { 2 - 3 } & $\begin{array}{c}\text { TLRH } \\
(\mathbf{n}=\mathbf{1 8})\end{array}$ & $\begin{array}{c}\text { RAH } \\
(\mathbf{n}=\mathbf{3 0})\end{array}$ & \\
\hline LVSI present & $8(44.4)$ & $16(53.3)$ & 0.77 \\
Positive lymph node metastases & $4(22.2)$ & $5(16.7)$ & 0.71 \\
Positive parametrial & $2(11.1)$ & $5(16.7)$ & 0.70 \\
involvement & & & \\
$\begin{array}{l}\text { Close/positive vaginal } \\
\text { margin involvement }\end{array}$ & $4(22.2)$ & $4(13.3)$ & 0.27 \\
Adjuvant treatment & & & \\
$\quad \begin{array}{r}\text { None } \\
\text { Radiotherapy }\end{array}$ & $8(44.4)$ & $14(46.7)$ & 0.80 \\
$\quad$ Concurrent chemoradiotherapy & $7(38.9)$ & $9(30.0)$ & \\
\hline
\end{tabular}

LVSI: Iymphovascular space invasion; RAH: Wertheim's radical abdominal hysterectomy; TLRH: total laparoscopic Wertheim's radical hysterectomy

node metastases, parametrial involvement or positive vaginal margin status between the two groups.

A total of $10(55.6 \%)$ and $16(53.3 \%)$ patients in the TLRH and $\mathrm{RAH}$ groups received adjuvant treatment, respectively $(p=0.80)$. In the TLRH group, 3 patients received only radiotherapy (2 patients had small field pelvic radiotherapy and brachytherapy, and 1 patient had standard field pelvic radiotherapy and brachytherapy), while 7 patients received concurrent chemoradiotherapy (6 patients had concurrent chemoradiotherapy with weekly cisplatin at $40 \mathrm{mg} / \mathrm{m}^{2}$, and 1 patient received concurrent cisplatin/5-fluorouracil with pelvic radiotherapy).

With a median follow-up of 37.3 (range 10-68) weeks in the TLRH group, $1(5.6 \%)$ patient had a recurrence of the cancer. This patient had FIGO stage IB2 primary endometroid adenocarcinoma of the cervix and micrometastases to two obturator lymph nodes. Although the patient was counselled to receive concurrent chemoradiotherapy, she unfortunately developed back pain one month after surgery, just prior to commencement of the adjuvant treatment. Computed tomography revealed the presence of right pelvic and para-aortic adenopathy, consistent with recurrence. In the RAH group, the median follow-up was 23 (range 4-63) weeks and 3 (10.0\%) 
recurrences were observed. The sites of recurrence in the RAH group were the vaginal vault, lumbar spine and retroperitoneal lymph nodes.

\section{DISCUSSION}

Minimally invasive surgery in gynaecological oncology took many years to be accepted into mainstream practice due to the fear of compromising the patient's oncologic outcome, as well as the need for additional training in advanced laparoscopic techniques. However, with the advancements in laparoscopic equipment and improvements in surgical techniques over the past decade, it is now part of mainstream practice to offer minimally invasive surgery for selected cases.

In oncology, for a new surgical technique to be accepted, operative outcomes including complication and long-term survival rates have to be analysed. Recent evidence from a few large case series show that TLRH is a safe procedure that does not affect oncologic outcome; TLRH was also shown to have the added benefits of laparoscopy, such as low blood loss, less wound pain, less wound infection and better cosmesis. (3,10-14,16) Published in 2010 and the only randomised phase II study on the subject, Naik et al's study compared laparoscopic-assisted radical vaginal hysterectomy (LARVH) with RAH in 13 women with stage IB1 cervical cancer (7 in the LARVH arm and 6 in the RAH arm over a period of 20 months). ${ }^{(13)}$ That small study confirmed the short-term surgical benefits of LARVH, but cautioned that LARVH is a less radical procedure than $\mathrm{RAH}$ and should be restricted to women with small tumours. ${ }^{(13)}$

In the literature, median blood loss has been reported to range from $55 \mathrm{~mL}$ to $400 \mathrm{~mL}$ for $\mathrm{TLRH}^{(3-15)}$ and from $800 \mathrm{~mL}$ to $1,500 \mathrm{~mL}$ for $\mathrm{RAH} .{ }^{(17)}$ The results of our study compared favourably with other series in the literature, with a significantly lower median blood loss for the TLRH group. In previous studies, the reported median operative time for TLRH ranged from 196 mins to 371 mins, ${ }^{(3-15)}$ whereas in our study, the median operative time for TLRH was 268 mins. This time was statistically similar to that of the RAH group in our study (240 mins; $p=0.44$ ).

In most TLRH studies, intraoperative complications rates ranged from $0 \%$ to $15 \%$, and complications included cystotomy, and ureteric, rectal and vascular injuries. ${ }^{(3-15)}$ This rate of intraoperative complications is similar to that for $\mathrm{RAH}$, which has been reported to range from $4.4 \%$ to $6.6 \%$ for urinary tract-related complications and $8.7 \%$ for other complications (e.g. nerves, intestinal and haemorrhage). ${ }^{(18,19)}$ In our study, 1 (5.6\%) patient from the TLRH group had a serious intraoperative complication (i.e. massive bleeding) that necessitated conversion to laparotomy, while no intraoperative complication was encountered in the RAH group.

On the other hand, the postoperative complication rates reported in most TLRH studies ranged from $4 \%$ to $40 \%$, with urological complications such as urinary tract infection, voiding dysfunction, and vesicovaginal or ureterovaginal fistulas being the most frequently reported complication. ${ }^{(3-17)}$ In contrast, the reported postoperative complication rates for $\mathrm{RAH}$ ranged from $4.4 \%$ to $20 \%$. $^{(18,19)}$ In our study, the overall postoperative complication rate for the TLRH group was $11.1 \%(n=2)$ - one voiding dysfunction and one ureterovaginal fistula. This rate was not statistically different from that of the RAH group $(13.3 \% ; p=0.49)$. The surgical results of our study indicate that when TLRH is conducted by experienced surgeons, it is a fairly safe procedure with complication rates not inferior to that of traditional $\mathrm{RAH}$.

Cancer relapse occurs even in early cervical cancer. In $\mathrm{RAH}$, the occurrence of cancer relapse was reported to range from $12 \%$ to $25 \%$. $^{(20,21)}$ Relapse rates from $0 \%$ to $13 \%$ have been reported in various TLRH studies with a median follow-up of 7-92 months..$^{(3-15)}$ In our study, the relapse rate in the TLRH group was $5.6 \%$, occurring in a patient with FIGO stage IB2 endometroid adenocarcinoma of the cervix. This rate was not inferior to the recurrence rate of the $\mathrm{RAH}$ group $(10.0 \% ; p=1.00)$. Port site metastases (PSMs) is another concern with laparoscopic procedures in cancer treatment. Studies have shown that most PSMs occur in women with ovarian cancers. $^{(22-24)}$ For cervical cancers, less than 20 cases of PSM have been reported, with the majority occurring in women with positive nodes and tumours with squamous histology. ${ }^{(23)}$ It has been hypothesised that PSM occurs as a result of iatrogenic tumour dissemination during the removal of positive nodes or during uterine manipulation. ${ }^{(13)}$ Recent publications of laparoscopic staging for gynaecological malignancies revealed that port site recurrence is rare for cervical cancers $(0.43 \%) .{ }^{23,24)}$ In our study, the removal of lymph nodes was done under direct vision through a 5-12 $\mathrm{mm}$ disposable port without contact with skin tissue, thus eliminating the need for an endobag. This technique has been utilised in our institution for the past 2.5 years for all cases of cervical and endometrial cancers managed via laparoscopy, and there have been no reports of PSM to date.

Intermediate and long-term survival data of patients who underwent TLRH is now available and has been published in several studies (Table IV)..$^{(3,4,10-12,14,15)}$ The study with the longest follow-up was conducted by Lee et al. ${ }^{(12)}$ There was a total of 139 women with FIGO stage IA2 to IIA cervical cancer in that study, and the percentage of disease-free patients and the overall survival rate were $91.01 \%$ and $92.78 \%$, respectively, with a median follow-up of 92.1 months. ${ }^{(12)}$ Since the present study was a pilot study with a median follow-up of 37.3 weeks (i.e. 8.6 months), we were unable to comment on intermediate or long-term survival. To address this, we have planned a future prospective cohort study comparing this group of patients with another group of patients who underwent $\mathrm{RAH}$ with a median follow-up of at least five years. The long-term survival outcome of patients who underwent TLRH from other studies are encouraging. ${ }^{(3-4,10-15)}$ 
Table IV. Outcomes of selected studies on total laparoscopic Wertheim's radical hysterectomy with intermediate and long-term follow-up.

\begin{tabular}{|c|c|c|c|c|c|c|c|}
\hline Study, yr & $\begin{array}{c}\text { No. of } \\
\text { patients }\end{array}$ & FIGO stage & $\begin{array}{c}\text { Intraoperative } \\
\text { complications } \\
(\%)\end{array}$ & $\begin{array}{c}\text { Postoperative } \\
\text { complications } \\
\text { (\%) }\end{array}$ & $\begin{array}{l}\text { Median } \\
\text { follow-up } \\
\text { (mths) }\end{array}$ & $\begin{array}{l}\text { Relapse } \\
\text { rate (\%) }\end{array}$ & $\begin{array}{l}\text { Survival } \\
\text { rate }(\%)\end{array}$ \\
\hline Spirtos et al, $2002^{(3)}$ & 78 & |A2-IB1 & 9.0 & 9.0 & 66.8 & 10.3 & 93.6 \\
\hline Pomel et al, $2003^{(4)}$ & 50 & IA1-IB1 & 2 & 4 & 44 & 6 & 98 \\
\hline Li et al, $2007^{(10)}$ & 90 & IB1-IIA & 8 & 40 & 26 & 13 & 90 \\
\hline $\begin{array}{l}\text { Pellegrino et al, } \\
2009^{(11)}\end{array}$ & 101 & IB1 & 2 & 24 & 30 & 10 & 95 \\
\hline Lee et al, $2010^{(12)}$ & 139 & $|A-| \mid A$ & 6.50 & 15.10 & 92.10 & 7.90 & 92.78 \\
\hline Park et al, 2011(14) & 125 & IB1-IB2 & NA & 10.4 & 53.0 & 10.4 & $\begin{array}{l}\text { IB1: } 96.0 \\
\text { IB2: } 83.0\end{array}$ \\
\hline Yan et al, 2011 ${ }^{(15)}$ & 240 & |A2-IIA & 7.08 & 9.16 & 35.00 & NA & $\begin{array}{l}\text { IB1: } 82.00 \\
\text { IB2: } 66.00\end{array}$ \\
\hline Present study & 18 & IA-IB2 & 5.6 & 11.1 & 8.6 & 5.6 & NA \\
\hline
\end{tabular}

FIGO: International Federation of Gynecology and Obstetrics; NA: not applicable

Based on the early data we have gathered and the findings of other studies, ${ }^{(3-15)}$ we have reviewed our selection criteria for TLRH for cervical cancer. We now offer TLRH to women with cervical tumours that are less than $4 \mathrm{~cm}$ in size (i.e. FIGO Stage IB1 or lower), no clinical or radiological evidence of distant metastases, and no histological-type squamous cell carcinoma, endocervical adenocarcinoma or adenosquamous carcinoma.

The main factor contributing to the poor pick-up of laparoscopy in oncologic surgery is the apparent long learning curve due to difficult techniques and the need for delicate teamwork. However, as many studies have shown, once this has been overcome, patients benefit from laparoscopy surgery due to the low perioperative complications rates and uncompromised survival rates. In a recent study that evaluated the learning curve for TLRH, the authors demonstrated that the learning curve improved after only 23 cases with the 'buddy operating' method, in which two surgeons operate together to increase the rate of skill acquisition. ${ }^{(25)}$ This method is also practised in our institution, and a reduction in the operative time for TLRH was noted with gained experience in the technique. In recent years, some promising results on the use of robot-assisted laparoscopic surgery in the management of early cervical cancer has been demonstrated. ${ }^{(26,27)}$ Robotassisted laparoscopic surgery offers the advantage of threedimensional vision, tremor reduction, greater intra-abdominal articulation and motion scaling, which may shorten the learning curve for laparoscopic surgery, but at an increased cost. Longterm randomised studies on these new surgical techniques are needed to establish their cost-effectiveness and longterm benefits.

In conclusion, although TLRH is a technically demanding technique with a steep learning curve, the preliminary results are promising. With appropriate patient selection and increased experience, TLRH can be a safe and effective procedure for the management of early cervical cancer in Singapore.

\section{REFERENCES}

1. Nezhat CR, Burrell MO, Nezhat FR, Benigno BB, Welander CE. Laparoscopic radical hysterectomy with paraaortic and pelvic bode dissection. Am J Obstet Gynecol 1992; 166:864-5.

2. Querleu D. Laparoscopic radical hysterectomy. Am J Obstet Gynecol 1993; 168:1643-5.

3. Spirtos NM, Eisenkop SM, Schlaerth JB, Ballon SC. Laparoscopic radical hysterectomy (type III) with aortic and pelvic lymphadenectomy in patients with stage I cervical cancer: surgical morbidity and intermediate follow-up. Am J Obstet Gynecol 2002; 187:340-8.

4. Pomel C, Atallah D, Le Bouedec G, et al. Laparoscopic radical hysterectomy for invasive cervical cancer: 8 year experience of a pilot study. Gynecol Oncol 2003; 91:534-9.

5. Abu-Rustum NR, Gemignani ML, Moore K, et al. Total laparoscopic radical hysterectomy with pelvic lymphadenectomy using the argon-beam coagulator: pilot data and comparison to laparotomy. Gynecol Oncol 2003; 91:402-9.

6. Nezhat F, Mahdavi A, Nagarsheth NP, et al. Total laparoscopic radical hysterectomy and pelvic lymphadenectomy using harmonic shears. J Minim Invasive Gynecol 2006; 13:20-5.

7. Frumovitz M, dos Reis R, Sun CC, et al. Comparison of total laparoscopic and abdominal radical hysterectomy for patients with early stage cervical cancer. Obstet Gynecol 2007; 110:96-102.

8. Ghezzi F, Cromi A, Ciravolo G, et al. Surgicopathologic outcome of laparoscopic versus open radical hysterectomy. Gynecol Oncol 2007; 106:502-6.

9. Malzoni M, Tinelli R, Cosentino F, Perone C, Vicario V. Feasibility, morbidity and safety of total laparoscopic radical hysterectomy with lymphadenectomy: our experience. J Minim Invasive Gynecol 2007; 14:584-90.

10. Li G, Yan X, Shang H, et al. A comparison of laparoscopic radical hysterectomy and pelvic lymphadenectomy and laparotomy in the treatment of Ib-Ila cervical cancer. Gynecol Oncol 2007; 105:176-80.

11. Pellegrino A, Vizza E, Fruscio $R$, et al. Total laparoscopic radical hysterectomy and pelvic lymphadenectomy in patients with Ib1 stage cervical cancer: analysis of surgical and oncological outcome. Eur J Surg Oncol 2009; 35:98-103.

12. Lee CL, Wu KY, Huang KG, Lee PS, Yen CF. Long-term survival outcomes of laparoscopically assisted radical hysterectomy in treating early-stage cervical cancer. Am J Obstet Gynecol 2010; 203:165.e1-7.

13. Naik R, Jackson KS, Lopes A, Cross P, Henry JA. Laparoscopic assisted radical vaginal hysterectomy versus radical abdominal hysterectomy - a randomised phase II trial: perioperative outcomes and surgicopathological measurements. BJOG 2010; 117:746-51.

14. Park NY, Chong GO, Hong DG, et al. Oncologic results and surgical morbidity of laparoscopic nerve-sparing radical hysterectomy in the treatment of FIGO stage IB cervical cancer: long term follow-up. Int J Gynecol Cancer 2011; 21:355-62. 
15. Yan X, Li G, Shang H, et al. Twelve-year experience with laparoscopic radical hysterectomy and pelvic lymphadenectomy in cervical cancer. Gynecol Oncol 2011; 120:362-7.

16. Pecorelli S. Revised FIGO staging for carcinoma of the vulva, cervix, and endometrium. Int J Gynaecol Obstet 2009; 105:103-4.

17. Berek JS, Hacker NF, eds. Practical Gynaecologic Oncology. PA: Lippincott Williams \& Wilkins; 2005.

18. Ralph G, Winter R, Michelitsch L, Tamussino K. Radicality of the parametrial resection and dysfunction of lower urinary tract after radical hysterectomy. Eur J Gynecol Oncol 1991, 12:27-30.

19. Zanoio L, Albiero A, Divirqilio G. [Radical hysterectomy. Operative complications]. Minerva Ginecol 1993; 45:591-6. Italian.

20. Landoni F, Maneo A, Colombo A, et al. Randomised study of radical surgery versus radiotherapy for stage Ib-Ila cervical cancer. Lancet 1997; 350:535-40.

21. Kinney WK, Alvarez RD, Reid GC, et al. Value of adjuvant whole pelvis irradiation after Wertheim hysterectomy for early stage squamous cell carcinoma of the cervix with pelvic nodal metastasis: a matched control study. Gynecol Oncol 1989; 34:258-62.

22. Martínez A, Querleu D, Leblanc E, Narducci F, Ferron G. Low incidence of port-site metastases after laparoscopic staging for uterine cancer. Gynecol Oncol 2010; 118:145-50.

23. Tjalma WA, Winter-Roach BA, Rowlands P, De Barros Lopes A. Port-site recurrence following laparoscopic surgery in cervical cancer. Int J Gynecol Cancer 2001; 11:409-12.

24. Zivanovic O, Sonoda Y, Diaz JP, et al. The rate of port-site metastases after 2251 laparoscopic procedures in women with underlying malignant disease. Gynecol Oncol 2008; 111:431-7.

25. Reade C, Hauspy J, Schmuck ML, Moens F. Characterizing the learning curve for laparoscopic radical hysterectomy: buddy operating as a technique for accelerating skill acquisition. Int J Gynecol Cancer 2011; 15:930-5

26. Magrina JF, Kho RM, Weaver AL, Montero RP, Magtibay PM. Robotic radical hysterectomy: comparison with laparoscopy and laparotomy. Gynecol Oncol 2008; 109:86-91.

27. Ramirez PT, Soliman PT, Schmeler KM, dos Reis R, Frumovitz M. Laparoscopic and robotic techniques for radical hysterectomy in patients with early stage cervical cancer. Gynecol Oncol 2008; 110(3 Suppl 2):S21-4. 